\title{
Entrepreneurship
}

Jul a Dez $2021-\mathrm{v} .5-\mathrm{n} .2$

ISSN: 2595-4318

This article is also available online at:

\section{A pesquisa de clima organizacional como ferramenta de diagnóstico organizacional}

O capital humano é considerado um diferencial competitivo nas empresas. Diante disso, são crescentes os investimentos em estratégias de gestão de pessoas que visam à retenção dos colaboradores. Com base nesse contexto, o presente artigo descreve o diagnóstico do clima organizacional da Locatio do Brasil, empresa do ramo de locação de equipamentos da construção civil, propondo ações de intervenção visando contribuir com a elevação o nível de satisfação dos funcionários no ambiente de trabalho. Trata-se de uma pesquisa que, quanto aos fins, é definida como descritiva e aplicada. Com relação aos meios, é uma pesquisa de campo realizada por meio de questionário estruturado, desenvolvido com bases em pesquisas bibliográficas tidas como fontes secundárias. A apuração dos resultados tratou de cinco grupos: ambiente de trabalho; tomada de decisão; sentimentos de realização, autonomia e responsabilidade profissional; reconhecimento, remuneração e benefícios; e relacionamento interpessoal. Em síntese, os dados obtidos sinalizaram instabilidade no ambiente organizacional, comprovada pela apuração das respostas que indicou o sentimento de insatisfação dos empregados, refletido nos resultados laborais. Enquanto propositura, indica-se à empresa o uso de metodologias de recursos humanos para minimizar, e/ou eliminar, fatores de insatisfação, tais como a criação de agenda de eventos para a socialização dos empregados, gestão participativa, plano de cargos e salários. Ademais, sugere-se a contratação de uma consultoria para dar continuidade às ações tendo em vista a melhoria do clima organizacional e, consequentemente, dos resultados laborais.

Palavras-chave: Clima Organizacional; Pesquisa de Clima; Diagnóstico Organizacional.

\section{Organizational climate research as an organizational diagnostic tool}

Human capital is considered a competitive advantage in companies. Therefore, investments in people management strategies that aim to retain employees are growing. Based on this context, this article describes the diagnosis of the organizational climate of Locatio do Brazil, a company in the construction equipment rental business, proposing actions of intervention aimed at contributing to the increase in the level of employee satisfaction in the work environment. It is a research that, in terms of ends, is defined as descriptive and applied. Regarding the means, it is a field research carried out through a structured questionnaire, developed based on bibliographic research considered as secondary sources. The verification of the results dealt with five groups: work environment; decisionmaking; feelings of accomplishment, autonomy and professional responsibility; recognition, compensation and benefits; and interpersonal relationships. In summary, the data obtained signaled instability in the organizational environment, evidenced by the verification of the responses that indicated the employees' feeling of dissatisfaction, reflected in the work results. As a proposal, the company is recommended to use human resources methodologies to minimize, and/or eliminate dissatisfaction factors, such as the creation of an event agenda for the socialization of employees, participatory management and a plan for jobs and salary. In addition, it is suggested to hire consulting services to continue the actions with intent to improve the organizational climate and, consequently, the work results.

Keywords: Organizational Climate; Climate research; Organizational Diagnosis.

Topic: Recursos Humanos

Reviewed anonymously in the process of blind peer
Received: $\mathbf{1 1 / 0 7 / 2 0 2 1}$

Approved: 25/09/2021
Fabrícia Julia da Silva (iD

Centro Universitário Newton Paiva, Brasil http://lattes.cnpq.br/0311513032486528

http://orcid.org/0000-0002-4069-2174

fabriciajulia.adm@gmail.com

Marina Reis Cláudio Calais (iD

Centro Universitário Newton Paiva, Brasil

http://lattes.cnpq.br/7728679820406903

http://orcid.org/0000-0001-8151-8298

marinanitas@yahoo.com.br

Sheyla Rosane de Almeida Santos (iD

Centro Universitário Newton Paiva, Brasil

http://lattes.cnpg.br/7451234004716790

http://orcid.org/0000-0002-6479-6832

sheylaalmeida3@outlook.com
6

DOI: 10.6008/CBPC2595-4318.2021.002.0003
Referencing this:

SILVA, F. J.; CALAIS, M. R. C.; SANTOS, S. R. A.. A pesquisa de clima organizacional como ferramenta de diagnóstico organizacional.

Entrepreneurship, v.5, n.2, p.23-35, 2021. DOI:

http://doi.org/10.6008/CBPC2595-4318.2021.002.0003 


\section{INTRODUÇÃO}

O aquecimento do setor da construção civil no Brasil tem proporcionado o crescimento de diversos setores, sendo o mercado de locação de máquinas e equipamentos um deles, pois, diferentes etapas de uma obra demanda a necessária utilização desse tipo de serviço.

De acordo com dados divulgados acerca do setor de construção civil, no ano de 2013 houve o crescimento de $1,9 \%$, tendo como meta para o ano seguinte, 2014 , um de crescimento $2,8 \%$, considerando o aporte de investimentos públicos e privados, a realização de eventos esportivos internacionais, como a Copa do Mundo e as Olimpíadas. O fato é que aspectos como os citados são fundamentais para a construção civil e, consequentemente, alavancam o mercado de locação de máquinas e equipamentos para o setor.

Direcionado para o referido contexto, o presente estudo foi desenvolvido na Locatio do Brasil S/A, uma empresa de locação de máquinas e equipamentos para a construção civil. Fundada em 1993, a empresa iniciou com a sociedade de dois irmãos, sendo inicialmente chamada Central Locação. Tratava-se de uma empresa familiar que tinha como principal atividade a locação de caçambas estacionárias. Desde a fundação, a empresa solidificou-se e destacou-se no segmento em que atua.

Em 2008, a empresa expandiu sua atuação, assumindo a razão social Locatio do Brasil S/A. Atualmente é uma sociedade anônima de capital fechado, que possui parcerias com a indústria da construção civil, oferecendo locações de máquinas, equipamentos e serviços de terraplanagem.

A Locatio do Brasil S/A é sediada no município de Contagem, Minas Gerais, mas Locatio atua em todo território nacional. Possui diversificada frota de equipamentos e um corpo técnico qualificado, o que possibilita a prestação de serviços de modo eficiente. A empresa conta com 48 empregados divididos entre as áreas administrativa e operacional.

De encontro com as expectativas do mercado de locação de maquinas, que vão da extensão de linhas de produtos, passando por excelência no atendimento e, por fim, pela agilidade na entrega do serviço, a empresa se posiciona como competitiva, pois oferece uma amplitude de produtos e serviços, tendo em vista satisfazer as necessidades dos contratantes em todas as etapas da obra.

Contudo, a Locatio do Brasil S/A faz parte de um mercado em constante expansão, o que demanda mão de obra especializada e qualificada. Assim, faz-se necessário constantes investimentos em estratégias de gestão de pessoas, tendo em vista a retenção dos empregados. Para tanto, é fundamental identificar as percepções dos empregados sobre as relações de trabalho, de modo que a empresa possa atuar em favor de promover a permanência deles.

Diante do contexto exposto, interessou-nos a possibilidade de diagnosticar o clima organizacional da referida empresa, com o intuito de apurar o que os empregados consideram como positivo e negativo no ambiente organizacional. Assim, foi formulado o seguinte questionamento: quais medidas precisam ser desenvolvidas na Locatio do Brasil S/A para promover maior satisfação dos empregados no ambiente de trabalho?

Tal objeto de pesquisa faz parte dos estudos de clima, os quais são particularmente úteis para as 
empresas, porque fornecem um diagnóstico geral da organização, além de apontar indicações sobre as áreas que demandam atenção especial. Ou outras palavras, "não basta sentir que o clima está mal, é preciso identificar onde, porque e como agir para melhorá-lo (SOUSA, 1982).

Assim, o objetivo norteador deste estudo foi avaliar o clima organizacional da Locatio do Brasil S/A, tendo em vista elevar o nível de satisfação dos empregados. Para tanto, foram definidos também os seguintes objetivos específicos: Identificar as percepções dos empregados acerca do ambiente de trabalho; Analisar os fatores que influenciam negativamente e/ou positivamente o clima organizacional; Propor ações que contribuam com a melhor gestão do clima organizacional.

Quanto à relevância desta temática, justifica-a mediante a evidenciação de que a pesquisa científica permite relacionar os estudos teóricos com a aplicabilidade da teoria na realidade organizacional. Isto é, permite contribuir, fundamentado em achados científicos, com a tomada de decisão gerencial, visando melhorias contínuas no ambiente de trabalho e, consequentemente, no desenvolvimento organizacional.

\section{REVISÃO TEÓRICA}

\section{Clima organizacional}

Em um cenário social e econômico marcado por constantes e aceleradas mudanças que movimentam o ambiente organizacional de forma global, as empresas se vêm cada vez mais obrigadas a buscar formas de acompanhar as inevitáveis evoluções. Tal conjuntura pode ser evidenciada a partir de Robbins (2009), ao relatar que "as organizações hoje enfrentam um ambiente cada vez mais dinâmico e mutável. Isso exige que elas se adaptem às novas condições".

No Brasil, de acordo Luz (2010), esta percepção teve início com a abertura da economia ao mercado na década de 90 , e com a posterior entrada de produtos e organizações estrangeiras, forçando as nacionais a adotarem uma série de estratégias para se manterem competitivas, tais como: intenso uso da automação, redução do quadro de pessoal, terceirização, reengenharia e downsizing, privatização, fusões, aquisições e alianças estratégicas. Essas práticas, ainda de acordo com Luz (2010), acarretam em insegurança e expressiva mudança na reação do empregado com relação à empresa.

Cabe salientar que nas práticas e políticas das empresas, estas alterações “[...] têm de se ajustar a um ambiente multicultural. As políticas e práticas de recursos humanos tiveram de mudar para conseguir atrair e reter essa força de trabalho mais diversa" (ROBBINS, 2009).

De acordo com Luz (2010) "toda vez que uma empresa é comprada, ou quando se funde com outra, instala-se um clima de insegurança entre os funcionários", o que contribui para a mudança do comportamento do trabalhador. Como consequência, o clima organizacional da empresa é impactado, tornando uma preocupação para os gestores e, principalmente, para a área de recursos humanos, que tem entre seus compromissos assegurar um clima agradável para alcançar os objetivos das organizações e do bem comum dos empregados.

Os estudos de clima organizacional não são perspectivas de análise recentes. Sua expansão ocorreu 
no início de 1924 após os experimentos de Hawthorne, que inicialmente tinham como foco verificar a influência da iluminação sobre a produtividade no ambiente de trabalho. Os estudos das ciências humanas trouxeram a preocupação a respeito da motivação, satisfação, estado psicológico do empregado e a necessidade de um ambiente de trabalho satisfatório no qual as pessoas se sintam bem para desempenhar suas atividades.

Assim, o clima organizacional passou a definido como o nível de satisfação dos empregados em relação ao seu ambiente de trabalho.

O clima retrata o grau de satisfação material e emocional das pessoas no trabalho. Observase que este clima influencia profundamente a produtividade do indivíduo e, consequentemente da empresa. Assim sendo, o mesmo deve ser favorável e proporcionar motivação e interesse nos empregados, além de uma boa relação entre os funcionários e a empresa. (LUZ, 2010)

Segundo Oliveira (2010), o clima organizacional é um estado interno vulnerável a acontecimentos externos e/ou internos da organização, podendo ser o motivo do desencadeamento de novos acontecimentos, decisões e ações estratégicas da mesma.

É neste contexto que o diagnóstico do clima organizacional se mostra como uma ferramenta eficiente para que o gestor conheça a percepção de seus empregados sobre o ambiente de trabalho, fundamentandoo na tomada de decisões mais assertivas quanto à gestão das pessoas.

O clima organizacional reflete o modo como as pessoas interagem umas com as outras, com os clientes e fornecedores internos e externos, bem como o grau de satisfação com o contexto que as cerca. O clima organizacional pode ser agradável, receptivo, caloroso e envolvente, em um extremo, ou desagradável, agressivo, frio e alienante em outro extremo. (CHIAVENATO, 2004)

Nesta perspectiva, Luz (2010) destaca que gerir o clima organizacional é essencial para qualquer empresa que busca excelência em sua área de atuação, favorecendo a manutenção de profissionais qualificados e satisfeitos. Contudo, o referido autor aponta que muitas empresas desconsideram que a satisfação dos seus clientes externos depende da satisfação dos clientes internos.

\section{A pesquisa de clima organizacional como ferramenta de diagnóstico organizacional}

Uma das formas desenvolvidas para avaliar o clima organizacional é desenvolver, mediante a obtenção de dados, estratégias para a manutenção e/ou melhoria do mesmo. A pesquisa de clima é uma ferramenta que possibilita identificar o grau de satisfação e insatisfação dos empregados, cujo resultado permite aos gestores planejar ações que poderão contribuir para a motivação e consequente satisfação dos empregados. De acordo com Gil (2011) "a pesquisa de clima organizacional é implementada com o objetivo de desenvolver a compreensão das gerências acerca dos pontos de vista dos empregados para melhorar as relações de trabalho com seus subordinados".

Chiavenato (2004) define a pesquisa de clima organizacional como sendo uma ferramenta segura e objetiva que não tem comprometimento com a situação vigente, mas que busca identificar problemas efetivos na gestão dos Recursos Humanos. O autor também defende que as análises, o diagnóstico e as sugestões provenientes dos resultados da pesquisa, são valiosos instrumentos para o sucesso de programas 
que tenham como foco a melhoria contínua da qualidade e o aumento da produtividade; ambos indispensáveis às empresas.

Oliveira (2010) aponta que o processo de pesquisa referente ao clima interno em uma organização pressupõe as seguintes etapas:

a) Identificar o público-alvo interno a ser pesquisado.

b) Levantar possíveis fatores sinalizadores do clima interno.

c) Selecionar os fatores mais promissores para pesquisar fatores que se refiram a aspectos da vida na empresa que presumivelmente mais impactam o clima.

d) Identificar indicadores adequados para a medição desses fatores.

e) Selecionar os instrumentos de pesquisa (questionário, entrevistas, etc.).

f) Proceder a coleta e o registro sistemático dos dados.

g) Tabular os dados coletados.

h) Interpretar as informações decorrentes da tabulação dos dados e tirar conclusões.

i) Produzir os relatórios sobre as conclusões extraídas da pesquisa.

j) Sugerir medidas gerencias relacionadas com os problemas ou situações verificadas.

k) Apresentar as conclusões da pesquisa à empresa.

Seguindo as etapas citadas, Oliveira (2010) afirma ser possível obter um diagnóstico confiável acerca do clima organizacional da empresa. Contudo, salienta que isso não garante a gestão propriamente dita do clima. O autor ressalta ainda ser expressiva a quantidade de empresas que realiza as pesquisas periodicamente, mas que não se preocupa em utilizar os resultados obtidos como base para planejarem uma estratégia, ou para estruturar um plano de ação em busca de soluções ou minimização dos problemas apontados.

\section{As vantagens de se medir o clima organizacional}

A necessidade de mensurar o clima organizacional como elemento atuante nas empresas, ainda que intangível, é um mecanismo capaz de fornecer aos gestores as informações necessárias para buscar a manutenção de conjunturas favoráveis para os envolvidos.

Por meio da pesquisa de clima é possível avaliar fatores tangíveis e intangíveis provenientes da perspectiva do empregado, e de acordo com a análise dos resultados, implementar melhorias organizacionais. Oliveira (2010) assevera que as avaliações resultantes tanto podem ser favoráveis quanto desfavoráveis, uma vez que devem considerar que o clima interno oscila, moderadamente, de semana a semana, de dia a dia e, em alguns casos, diz até que de hora em hora, dependendo do estilo de liderança da empresa. Segundo o autor:

Em condições normais, portanto, desde que não sobrevenham eventos influenciadores imprevistos que sejam excepcionalmente importantes, a "oscilabilidade" (perdão pelo neologismo) do clima não chega a ser assim tão acentuada no curto prazo, embora ela possa sofrer grandes oscilações em médios e longos prazos. (OLIVEIRA, 2010)

O fato é que tendo em vista a ocorrência das referidas oscilações no clima organizacional, há muito questionamento sobre o porquê de as empresas deverem se preocupar com isso. Assim, entre outras coisas, indagam: Porque gastar/investir recursos financeiros, humanos e tempo para aplicar uma pesquisa de clima? 
De acordo com a Fundação Nacional de Qualidade:

No contexto corporativo atual, em que mudanças ocorrem a todo o momento, as organizações precisam ter estratégias definidas, sustentadas por uma gestão que estimule o envolvimento e a participação dos empregados. Para isso é importante avaliar o clima organizacional e, a partir dos resultados, elaborar e implementar planos de melhorias. (FNQ, 2007)

Ao mensurar o clima organizacional, as empresas obtêm um diagnóstico mais preciso sobre as próprias condições de trabalho, bem como sobre os itens que intervêm positivamente e negativamente no ambiente organizacional. Assim, Gil (2011) aponta as seguintes vantagens de medir o clima organizacional:

Identificar e mensurar as atitudes dos empregados para com os programas, políticas e possibilidades práticas da empresa. De posse desses dados, a empresa poderá avaliar os efeitos das decisões anteriores e promover mudanças onde for conveniente; desenvolver a compreensão das gerências acerca dos pontos de vista dos empregados para melhorar as relações de trabalho com seus subordinados; identificar as tendências de opiniões e atitudes dos empregados. Comparando-se os resultados de levantamentos sucessivos, torna-se possível antecipar tendências que poderão influir no comportamento dos empregados. Dessa forma, a pesquisa de clima organizacional poderá constituir um verdadeiro "sistema de alerta preventivo"; subsidiar estudos acerca da eficiência organizacional. Os dados obtidos podem ser utilizados para uma melhor compreensão acerca dos fatores que intervém na satisfação e na moral do empregado; demonstrar o interesse da empresa nas opiniões dos empregados para melhorar a qualidade de vida no trabalho. (GIL, 2011)

Cabe ainda destacar que de acordo com Chiavenato (2004), o clima organizacional é diretamente proporcional à satisfação, ou seja, quanto maior for a satisfação das pessoas, maior será o nível do clima organizacional. Consequentemente, quanto menor for a satisfação, menor será o nível do clima organizacional.

Desta feita, percebe-se que a pesquisa de clima organizacional é um instrumento importante de diagnóstico para a tomada de decisão gerencial, e deve ser utilizado cuidadosamente, uma vez que influencia em diversos contextos, dentre os quais as estratégias organizacionais.

\section{METODOLOGIA}

Tendo como base os fundamentos de Vergara (2004), para alcançar os objetivos propostos neste estudo, apresentar-se-á algumas considerações a respeito da metodologia a ser adotada. De acordo com a autora, a metodologia consiste em métodos para atingir determinado fim, considerando o método como uma lógica de pensamento a ser seguida. O tipo de pesquisa empregada, segundo a autora, deve ser classificado considerando dois aspectos: quanto aos fins e quanto aos meios.

Quanto aos fins, esta pesquisa é descritiva e aplicada. Descritiva pois tem como objetivo expor as características dos fenômenos identificados na empresa, e estabelecer as possíveis correlações entre as variáveis, definindo sua natureza. Será aplicada por ter uma finalidade prática, isto é, "motivada pela necessidade de resolver problemas concretos, mais imediatos, ou não" (VERGARA, 2004).

Quanto aos meios, a investigação ocorreu mediante a pesquisa de campo, tendo como fonte secundária a pesquisa bibliográfica, que possibilitou aos investigadores fundamentarem a teoria, a citar os indicadores de clima organizacional propostos por Luz (2010) utilizados para estabelecer os critérios a serem 
investigados.

A pesquisa de campo foi desenvolvida por meio da aplicação de um questionário fechado e estruturado, no qual o respondente ponderou diante das alternativas apresentadas em cada questão. A pesquisa é classificada como qualitativa, pois, após coletados os dados, as respostas tabuladas e os resultados apresentados em forma de gráficos foram analisadas com a finalidade de realizada uma análise compor os resultados sobre a percepção dos empregados referente aos indicadores de clima.

Os sujeitos que compuseram esta pesquisa foram os 15 empregados da área administrativa da Locatio do Brasil S/A. Considerando a facilidade de acesso a todos os empregados da empresa, não houve processo de seleção da amostra, ou seja, o questionário foi aplicado a todo universo de pesquisa.

\section{RESULTADOS E DISCUSSÃO}

\section{Pesquisa de Clima}

Para diagnosticar o ambiente da empresa, foi aplicada a pesquisa de clima organizacional aos 15 empregados da área administrativa da Locatio do Brasil S/A. Os dados apurados foram divididos em 5 categorias, que após analisadas, possibilitaram o diagnóstico do clima organizacional da empresa. Tais achados foram utilizados na elaboração de planos de ações cujo intuito é contribuir para a melhor gestão do clima.

\section{Ambiência do trabalho}

Inicialmente foi analisada a ambiência do trabalho. Neste quesito, os empregados foram questionados acerca de cinco fatores que envolvem o ambiente organizacional no qual eles estavam inseridos. Quando questionados se a empresa é um bom lugar para trabalhar, metade dos empregados (50\%) disseram que sim, enquanto $42 \%$ não ter certeza se é ou não um bom lugar para se trabalhar, e $8 \%$ disseram que não.

Questionados se a existência de boas condições físicas e psicológicas são imprescindíveis para a produtividade e satisfação no trabalho, $50 \%$ dos empregados disseram não ter certeza quanto às condições de trabalho oferecidas pela empresa, sendo que 33\% disseram não serem satisfatórias e $17 \%$ afirmaram estarem satisfeitos.

A qualidade do trabalho executado nas empresas deveria ser vista como prioridade à cerca da quantidade de trabalho, pois tal relação é extremamente positiva para o clima organizacional. No entanto, a maioria dos respondentes (42\%) disseram não ter certeza sobre perceber a qualidade como primordial, tendo $33 \%$ de funcionários que afirmam perceber que a qualidade do trabalho prestado com maior respaldo que a quantidade de trabalho, e os demais, 25\%, que disseram que não perceber está relação.

Além de estar bem preparado para assumir uma determinada função, o empregado deve receber volume de trabalho em conformidade com suas habilidades. A esse respeito, 50\% disse não ter certeza sobre estarem satisfeitos com o volume de trabalho oferecido a eles, sendo que $33 \%$ se disseram satisfeitos, e 
apenas $17 \%$ afirmaram não estarem satisfeitos. Em relação aos padrões éticos no ambiente de trabalho, 58\% disseram não ter certeza que a empresa atua sob valores éticos, $25 \%$ afirmaram que a empresa não atua, e os demais $17 \%$ consideram que a empresa atua sob valores éticos.

Sobre o atendimento aos clientes, 50\% dos empregados percebem que a empresa atende prontamente às necessidades do cliente. Já os demais variaram no mesmo percentual, com $25 \%$ afirmando não teve certeza e $25 \%$ acreditando que a empresa atende aos clientes da melhor maneira possível. Cabe salientar que um ambiente de trabalho saudável pode contribuir para melhorar o relacionamento interpessoal e a produtividade, além de ser favorável para reduzir o nível de absenteísmo e rotatividade de pessoal.

\section{Tomada de decisão}

Foram analisadas as participações dos empregados e gestores com relação às orientações de trabalho e aos processos de tomada de decisões.

Questionados se recebem orientações claras e objetivas sobre o trabalho a ser desenvolvido, $58 \%$ afirmaram ter recebido as devidas orientações para a execução de suas atividades, enquanto $25 \%$ disseram não as ter recebido, e 17\% relataram não ter certeza se receberam todas as informações que deveriam.

Sobre o processo de tomada de decisão, os empregados foram questionados se a empresa os explica sobre as decisões tomadas. Conforme os dados apurados, $84 \%$ dos empregados consideraram que não recebem explicações quanto às decisões tomadas, e dos $16 \%$ restante, metade (8\%) não tem certeza se recebem as justificativas que acreditam ser necessárias, e somente a outra metade (8\%) diz receber explicações suficientes acerca das decisões tomadas.

Embora maioria expressiva dos empregados tenham afirmado na questão anterior que não recebem explicações suficientes quanto às decisões tomadas, 50\% deles disseram confiar nas mesmas. Já para 33\% dos funcionários, não há certeza sobre esse sentimento de confiança, e 17\% declaram não confiar.

Os fatores apontados neste momento dos resultados envolvem princípios de uma gestão participativa que, entre outros aspectos, tem como vantagem a participação dos empregados na tomada de decisões da empresa, gerando desenvolvimento e aumento da produtividade.

\section{Sentimentos de realização, autonomia e responsabilidade profissional}

Os empregados também foram questionados sobre o nível de responsabilidade, autonomia e realização no trabalho. $\mathrm{O}$ sentimento de realização profissional é extremamente positivo para a satisfação e motivação do sujeito, contribuindo para ampliar a produtividade organizacional. A este respeito, $42 \%$ disseram não ter certeza quanto ao que sentem, enquanto $33 \%$ negaram se sentir realizados, e apenas $25 \%$ dos empregados declararam sentirem-se realizados.

Questionados sobre a responsabilidade individual na contribuição do sucesso organizacional, $92 \%$ dos empregados assumiram a responsabilidade de contribuir para tal, e apenas $8 \%$ disseram que não se sentem responsáveis por isso. 
Sobre se sentirem aptos para receber ainda mais responsabilidades, $75 \%$ dos respondentes declararam estar preparados para novas responsabilidades, seguidos por $17 \%$ que não têm certeza, e apenas $8 \%$ que afirmaram não se sentirem aptos para receberem novas responsabilidades.

O empregado ter a sensação de liberdade para executar o trabalho é apontado como motivador e positivo para ambos, o funcionário e a organização. Na empresa foco nesta análise, $67 \%$ dos participantes desta pesquisa disseram sentir-se livres para realizar o trabalho da maneira que consideram melhor, sendo que $33 \%$ afirmaram não tem certeza quanto a este sentimento.

Quando questionados se sentem seguros para se expressarem livremente dentro da empresa, 59\% disseram não ter esta sensação de liberdade, seguidos por $33 \%$ que afirmaram não têm certeza quanto a isso, e por apenas $8 \%$ que declararam que sim, sentem-se seguros para se expressarem livremente.

Estes são fatores que embora possam soar subjetivos, devem ser levados em consideração, pois os sentimentos de realização, autonomia e responsabilidade profissional são necessários para que os empregados possam exercer suas funções da melhor maneira possível.

\section{Reconhecimento, remuneração e benefícios}

Foram analisadas as percepções dos empregados quanto aos fatores de reconhecimento, remuneração e benefícios oferecidos pela empresa. Questionados sobre a adequação da remuneração à função exercida, $50 \%$ dos empregados não têm certeza se são remunerados adequadamente, $42 \%$ afirmaram não serem e apenas $8 \%$ estão satisfeitos com a remuneração que recebem.

Ser reconhecido pelo o desempenho é uma necessidade do ser humano, e a este respeito, $42 \%$ dos respondentes desta pesquisa não têm certeza, mesma porcentagem dos que afirmaram não serem devidamente reconhecidos. Neste quesito, apenas $16 \%$ acreditam que são reconhecidos pela empresa.

Outra maneira de gerar reconhecimento e satisfação no trabalho é por meio da concessão de benefícios. Na empresa em questão, $58 \%$ dos funcionários que responderam aos questionários declararam que não estão satisfeitos. Quanto aos demais, $25 \%$ não têm certeza e $17 \%$ disseram estar satisfeitos com os benefícios oferecidos pela empresa.

O quesito reconhecimento, remuneração e benefícios tem se tornado fator de expressiva relevância na captação ou retenção de empregados, pois, tendo em vista a competitividade entre as empresas e a carência de mão de obra qualificada, muitas organizações implementam ações continuas para não perderem funcionários.

\section{Relacionamento interpessoal}

A última categoria dos resultados obtidos junto aos funcionários tratou sobre o relacionamento interpessoal entre empregados e gestores.

Os respondentes sobre questionados se consideravam que conheciam as expectativas dos superiores em relação ao trabalho deles. Como resultado, $42 \%$ declaram não saber o que seus superiores esperavam deles, $33 \%$ afirmara saber e $25 \%$ declararam não têm certeza sobre isso. 
Ao indagar se os superiores consideravam as sugestões dos seus empregados, diagnosticou-se que $34 \%$ afirmaram que são ouvidos, sendo que entre os demais empregados, 33\% disseram que não são ouvidos por seus superiores, e o mesmo percentual (33\%) opinou que não têm certeza. Sobre a avaliação do superior com relação aos empregados, $42 \%$ consideraram que não são avaliados justamente, $33 \%$ não têm certeza da avaliação dos superiores, e $25 \%$ dos empregados disseram que se sentem avaliados justamente.

Sobre o incentivo da empresa para o trabalho em equipe, 50\% não têm certeza se há tal incentivo, já $33 \%$ afirmam que o trabalho em equipe não é incentivado, e apenas $17 \%$ disseram que são incentivados a trabalharem em equipe. Questionados se gostam do próprio trabalho, 83\% declararam que gostam do trabalho que realizam e $17 \%$ não têm certeza. Neste item, ninguém afirmou não gostar do trabalho que executa na empresa.

Outro determinante do clima organizacional é a segurança que o empregado sente em relação à própria situação de empregabilidade. Neste caso, 50\% não têm certeza sobre esta segurança, já 33\% não se sentem seguros, e $17 \%$ afirmaram ter sentimento de segurança com relação ao emprego.

Por fim, os empregados foram questionados se indicariam alguém de seu convívio para trabalhar nesta empresa. Em resposta, 50\% deles afirmaram que indicariam, enquanto $25 \%$ não indicariam e $17 \%$ não têm certeza. Os achados apresentados neste item ressaltam que a atuação voltada para o desenvolvimento gerencial e a implantação de uma política de Gestão de Pessoas pode minimizar os fatores considerados negativos e, consequentemente, melhorar o clima organizacional.

\section{Visão Geral}

De acordo com os dados apresentados, pode-se perceber que os empregados gostam do próprio trabalho e indicariam um amigo ou parente para trabalhar na empresa em questão, o que é um bom indicador. Porém, a maioria não sente realização, segurança, estabilidade no emprego e, além disso, não percebe o incentivo ao trabalho em equipe, nem se sentem reconhecidos e satisfeitos com a remuneração e os benefícios oferecidos.

Os indicadores pesquisados sobre a ambiência do trabalho quase sempre foram imprecisos, pois, na maioria das vezes, os empregados marcaram a opção "Não tenho certeza", quando questionados se a empresa é ou não um bom lugar para trabalhar, sobre as condições de trabalho oferecidas, sobre a qualidade do trabalho, o volume de trabalho e os padrões éticos no ambiente laboral.

A maior parte dos empregados também se queixou de não receber as devidas orientações para a execução de seus trabalhos, e nem explicações quanto às decisões tomadas pelos superiores, apesar de confiar em tais decisões.

Também se destacou o fato de que grande parte dos empregados declaram não possuir autonomia e não saber o que os superiores esperam deles. Acrescido a isso, não se sentem ouvidos e nem percebem uma avaliação justa por parte de seus superiores, apesar de $75 \%$ afirmarem que sentem preparados para assumirem novas responsabilidades, e de $92 \%$ saber que o sucesso organizacional depende de seu desempenho. 


\section{Sugestões}

Ao analisar os dados apresentados neste artigo, percebe-se a importância da pesquisa de clima como uma ferramenta de diagnóstico organizacional para a tomada de decisão gerencial. O resultado da pesquisa evidenciou como a ausência de ferramentas de Gestão de Pessoas propicia aspectos como alta vulnerabilidade ao clima organizacional, falta de equidade no ambiente de trabalho e fragilidades no gerenciamento de pessoas.

Sugere-se, a partir destas análises, a construção de um plano de ação seguindo o modelo de 5W2H, em que se determina para cada problema identificado: o que será feito para resolver cada problema, quem terá a responsabilidade de realizar a atividade, quando deverá ser feita, porque fazer, onde será feita, como deve ser feita e quanto poderá custar à empresa.

Com esta ferramenta é possível especificar claramente os passos a serem seguidos para que seja possível buscar um resultado positivo para os problemas identificados. A abaixo, a tabela 1 apresenta o plano de ação sugerido.

Tabela 1: Plano de ação Plano de Ação - Locatio do Brasil S.A.

\begin{tabular}{|c|c|c|c|c|c|}
\hline What - O quê? & Who - Quem? & When - Quando? & Where - Onde? & Why - Por que? & How - Como \\
\hline $\begin{array}{l}\text { Café com } \\
\text { Gestor }\end{array}$ & $\begin{array}{l}\text { O gestor com } \\
\text { sua equipe }\end{array}$ & Mensalmente & $\begin{array}{l}\text { Na própria } \\
\text { empresa }\end{array}$ & $\begin{array}{l}\text { Para melhorar o } \\
\text { relacionamento da } \\
\text { equipe com o gestor. }\end{array}$ & $\begin{array}{l}\text { Por meio de reuniões com } \\
\text { datas e horários pré- } \\
\text { determinados nas quais os } \\
\text { assuntos a serem tratados são } \\
\text { divididos em três: pontuados } \\
\text { pelo gestor, pautados pela } \\
\text { equipe; tema livre. }\end{array}$ \\
\hline $\begin{array}{l}\text { Gestão } \\
\text { Participativa }\end{array}$ & $\begin{array}{l}\text { O gestor com } \\
\text { sua equipe }\end{array}$ & Semanalmente & $\begin{array}{l}\text { Na própria } \\
\text { empresa }\end{array}$ & $\begin{array}{l}\text { Para aumentar o nível } \\
\text { de segurança dos } \\
\text { empregados a respeito } \\
\text { das decisões tomadas. }\end{array}$ & $\begin{array}{l}\text { Por meio de apresentações } \\
\text { formais ou informais, } \\
\text { considerando a relevância da } \\
\text { decisão tomada, em que o } \\
\text { gestor expõe aos empregados } \\
\text { o desenvolvimento das } \\
\text { atividades da empresa. }\end{array}$ \\
\hline $\begin{array}{l}\text { Plano de Cargos } \\
\text { e Salários }\end{array}$ & $\begin{array}{l}\text { Recursos } \\
\text { Humanos }\end{array}$ & Anualmente & $\begin{array}{l}\text { Na própria } \\
\text { empresa }\end{array}$ & $\begin{array}{l}\text { Para melhorar a } \\
\text { percepção do } \\
\text { empregado quanto à } \\
\text { equidade nas } \\
\text { distribuições de tarefas, } \\
\text { funções e } \\
\text { remunerações. }\end{array}$ & $\begin{array}{l}\text { Descrever os cargos, } \\
\text { estabelecer uma pesquisa e } \\
\text { tabela salarial, para } \\
\text { estabelecer uma política de } \\
\text { remuneração adequada à } \\
\text { classificação dos cargos. }\end{array}$ \\
\hline $\begin{array}{l}\text { Práticas e } \\
\text { Metodologias } \\
\text { Vivenciais }\end{array}$ & $\begin{array}{l}\text { A equipe com } \\
\text { o gestor }\end{array}$ & Mensalmente & $\begin{array}{l}\text { Na própria } \\
\text { empresa }\end{array}$ & $\begin{array}{l}\text { Para melhorar o } \\
\text { relacionamento entre } \\
\text { os empregados }\end{array}$ & $\begin{array}{l}\text { Por meio de práticas vivenciais } \\
\text { sugeridas pelos próprios } \\
\text { empregados, nas reuniões de } \\
\text { "Café com o gestor". }\end{array}$ \\
\hline $\begin{array}{l}\text { Plano de } \\
\text { Carreira e } \\
\text { Sucessão }\end{array}$ & $\begin{array}{l}\text { Recursos } \\
\text { Humanos }\end{array}$ & Anualmente & $\begin{array}{l}\text { Na própria } \\
\text { empresa }\end{array}$ & $\begin{array}{l}\text { Para melhorar a } \\
\text { percepção do } \\
\text { empregado em relação } \\
\text { à sua segurança no } \\
\text { emprego atual. }\end{array}$ & $\begin{array}{l}\text { Explicitar em uma Política de } \\
\text { Gestão de Pessoas as regras } \\
\text { que devem ser consideradas } \\
\text { para contratação, promoção e } \\
\text { desligamento. }\end{array}$ \\
\hline
\end{tabular}

Espera-se que com a aplicação das ações sugeridas, os empregados se sintam mais valorizados, mudem suas percepções perante aos aspectos pesquisados, bem como de outros que podem influenciar negativamente no clima da empresa, contribuindo até mesmo para que a empresa tenha melhores 
resultados.

\section{CONCLUSÕES}

O presente estudo teve como objetivo norteador avaliar o clima organizacional da Locatio do Brasil $\mathrm{S} / \mathrm{A}$, tendo em vista elevar o nível de satisfação dos empregados. Assim, foi possível identificar quais medidas precisam ser desenvolvidas para tal finalidade. Cabe salientar que as medidas apresentadas são sugestões resultantes da pesquisa de clima aplicada e foram devidamente enumeradas e descritas no plano de ação (tabela 1).

Os objetivos definidos nesta pesquisa foram alcançados, uma vez que para identificar as percepções dos empregados acerca do ambiente de trabalho, foi aplicada a pesquisa de clima. Deste modo, foram analisados os fatores que influenciam negativamente e/ou positivamente o clima organizacional.

A aplicação e apuração dos resultados da pesquisa de clima permitiu a quantificação da percepção dos empregados acerca dos aspectos que impactam no clima. Tais dados fundamentaram um plano de ação que pode contribuir para a melhoria da gestão. Os aspectos pesquisados foram divididos em cinco categorias: ambiente de trabalho; tomada de decisão; sentimentos de realização, autonomia e responsabilidade profissional; reconhecimento, remuneração e benefícios; e por fim, relacionamento interpessoal.

Como sugestão à empresa, considerou-se o desenvolvimento de diversas ações de Gestão de Pessoas, pois, implantar novos processos pode contribuir para a tomada de decisão gerencial e, consequente, para a melhoria do ambiente de trabalho.

Ainda pode-se sugerir à empresa, a realização de uma pesquisa de cultura para verificar a influência da mesma sobre o clima, uma vez que, entende-se a cultura como determinante do clima. Uma cultura flexível, atenta às necessidades dos empregados, favorece o clima de satisfação dos mesmos, enquanto que uma cultura resistente a mudanças, apegada à manutenção do status quo, influencia diretamente em um clima desfavorável.

Com o resultado da pesquisa de cultura organizacional, sugere-se à empresa que desenvolva um plano de desenvolvimento gerencial para ampliar as competências de seus líderes e, como consequência, buscar a melhoria do clima organizacional.

Para a realização deste estudo, foi considerada uma dificuldade o tempo insuficiente para a aplicação das sugestões do plano de ação, o que impossibilitou a mensuração das possíveis melhorias provenientes das mudanças recomendadas.

Como proposta de continuidade, sugere-se a aplicação de uma pesquisa de cultura organizacional para diagnosticar o estilo de liderança encontrado na Locatio e, a partir daí, criar ações que promovam o desenvolvimento gerencial, que gere impacto positivo no clima organizacional, e que resulte em consequente aumento da satisfação dos empregados. Para que o trabalho seja realizado de forma mais segura, propõe-se a contratação de uma consultoria. 


\section{REFERÊNCIAS}

CHIAVENATO, I.. Gestão de pessoas: e o novo papel dos recursos humanos nas organizações. Rio de Janeiro: Elsevier, 2004.

FNQ. Fundação Nacional de Qualidade. Avaliar o clima organizacional é fundamental na implementação de melhorias. Brasília: FNQ, 2007.

GIL, A. C.. Gestão de pessoas: enfoque nos papéis profissionais. São Paulo: Atlas, 2011.

\section{LOCATIO LOCAÇÕES E SERVIÇOS. Apresenta os serviços e} produtos fornecidos pela organização. São Paulo:

Locatiobrasil, 2020.
LUZ, R.. Gestão do clima organizacional. Rio de Janeiro: Qualitymark, 2010

OLIVEIRA, M. A.. Comportamento organizacional para a gestão de pessoas: como agem as empresas e seus gestores. São Paulo: Saraiva, 2010.

ROBBINS, S. P.. Comportamento organizacional. 11 ed. São Paulo: Pearson Prentice Hall, 2009.

SOUSA, E. L. P.. Clima e motivação em uma empresa estatal. Revista de Administração de empresas, Rio de Janeiro, v.22, n.1, p.14-18, 1982.

VERGARA, S. C.. Projetos e relatórios de pesquisa em administração. 5 ed. São Paulo: Atlas, 2004.

A CBPC - Companhia Brasileira de Produção Científica (CNPJ: 11.221.422/0001-03) detém os direitos materiais desta publicação. Os direitos referem-se à publicação do trabalho em qualquer parte do mundo, incluindo os direitos às renovações, expansões e disseminações da contribuição, bem como outros direitos subsidiários. Todos os trabalhos publicados eletronicamente poderão posteriormente ser publicados em coletâneas impressas sob coordenação da Sustenere Publishing, da Companhia Brasileira de Produção Científica e seus parceiros autorizados. Os (as) autores (as) preservam os direitos autorais, mas não têm permissão para a publicação da contribuição em outro meio, impresso ou digital, em português ou em tradução. 